\title{
Assessing the effect of a white Portland cement admixture on the early frost-thaw resistance of NHL-based masonry mortar
}

\author{
Frowin Ruegenberg (D) Martin Schidlowski - Franz Brunner • Erik Kirkwood • \\ Thomas Bidner • Anja Diekamp
}

Received: 21 July 2021 / Accepted: 14 December 2021 / Published online: 24 December 2021

(C) The Author(s) 2021

\begin{abstract}
Well preserved mortars based on natural hydraulic lime are widely spread in historical buildings throughout the alpine area of Tyrol, Austria. These are frequently restored with mortars oriented on historical models. Portland cement is also commonly used to modify these materials on building sites to speed up the setting time to improve the early frostthaw resistance, primarily when they are applied around the winter season. Therefore, it was our objective to specify the application potentials of those materials, respecting the intended use and the atmospheric conditions. Moreover, we tried to figure out the possible benefits and risks when using NHL-based materials, optionally modified by cement, yielding
\end{abstract}

Supplementary Information The online version contains supplementary material available at https://doi.org/10.1617/ s11527-021-01848-x.

F. Ruegenberg $(\square) \cdot$ M. Schidlowski · A. Diekamp Unit of Material Technology, University of Innsbruck, Technikerstraße 13, 6020 Innsbruck, Austria

e-mail: Frowin.Ruegenberg@uibk.ac.at

F. Brunner

Restaurator Franz Brunner, Langgasse 53, 6065 Thaur, Austria

E. Kirkwood

6020 Innsbruck, Austria

T. Bidner

Ingenieurbüro Bidner, Angererweg 13, 6075 Tulfes, Austria stable recommendations for the work with corresponding mortars. Hence, we examined the development of strength and water transport, also the frostthaw durability in a temporal context. The obtained results were compared with findings of assessing both materials under variable weather conditions around the winter season. Accordingly, the use of pure NHLbased lime mortars resulted as being critical mainly until about two months before intense frost conditions. Cement effectively contributes to the rapid hydraulic setting reaction in NHL-based materials. Hence, we recommend measured cement additions in areas where strong frost is expected after a few weeks and especially targeted in areas where carbonation is hindered because of excess moisture. Nevertheless, the potential use of Portland cement should be properly controlled in historic building preservation. A systematical approach that considers the framework conditions and the corresponding application to an area is essential to assure an appropriate conservation outcome.

Keywords Natural hydraulic lime NHL · Early frost-thaw load · Durability · Portland cement . Carbonation · Hydraulic reaction - Application field . Restoration 


\section{Introduction}

Tyrol is an alpine region in Austria rich in a variety of historic buildings that are undergoing a great deal of conservation work. Many prominent castles and palaces are preserved as ruins nowadays, embedded in a unique landscape. They are exceptional locations and therefore important destinations for tourists and excursion trips, which makes their preservation and maintenance an important issue for authorities responsible for historical building conservation. The useful life of most parts of the mentioned monuments corresponds to the medieval period, where natural hydraulic lime was primarily used as binder for the historical mortars in the alpine area [1]. Hence, modern NHL lime mortar has become increasingly used in recent restoration works for replacing and rebuilding projects, especially for its beneficial workability properties, long term durability and for its compatibility with the structures [2].

The hardening of NHL-based mortars is characterized by a two-stage process consisting of the hydraulic reaction of calciumsilicates and calciumaluminates and the carbonation of the lime-component, present as portlandite $\left(\mathrm{Ca}(\mathrm{OH})_{2}\right)$ in the binder. The development of these two reactions is primarily dependent on the moisture conditions in the mortar matrix and the pore space. Thus, the focus point moves from hydraulic reaction in early ages to carbonation in mature state [3]. However, the steady reaction behavior of the main hydraulic phase dicalciumsilicate $\left(\mathrm{C}_{2} \mathrm{~S}\right)$, dependent among other aspects on its crystal modification and the framework conditions, has to be taken into consideration when the general reaction performance of this complex material shall be described [4]. Hence, the special composition of NHL leads to a unique hardening behavior that is even more complex when the time factor and the real conditions have to be taken into account $[5,6]$.

Consequently, several aspects should be respected when working with NHL on the building site due to its particular properties. Besides the consideration of requirements regarding the adequate preparation of the substrate, the treatment and the protection of freshly applied mortar from atmospheric influences, the applicability of the mortars in frosty environments is an important and critical issue (e.g. [7]). Hence, the main question in detail is concerning the duration of the time period that has to be respected for a sufficient hardening of the mortar before the occurrence of the frost phase. The time limitations on building site works in alpine environment leads to the fact that repair works just before the occurrence of winter frost were made, even though those generally should be avoided. In addition to this, extreme weather events in the spring can go along with temperatures below zero degrees, which bears additional damaging load to the masonry. Therefore, NHL-based mortars on building sites become frequently enriched with minor admixtures of (white) Portland cement to improve their hardening speed and their resistance to frost-thaw load in early ages [8]. The topic has been investigated in a broad, systematical research study [2]. It covers the determination of several hardened mortar parameters of similar materials, guiding to a general compatibility assessment, but skipping the durability issue. Additionally, an applied study with focus on analogous materials, but working with other weathering stresses and differing time scales is available [9]. However, we treated the issue using a practical approach by comparing two NHL-based masonry mortar mixtures. The first one contained pure NHL 5 (acc. to the standard for building lime EN 459-1 [10]) as binder. The second one was enriched with $5 \mathrm{wt} \%$ of white Portland cement (referred to total mortar weight), to improve the development of their resistance against frost in the first weeks after application. The chosen quantity is oriented on a typical "bucket forefront" that is in widespread use by restorers for the described reasons and oriented on the admixed amount mentioned in [9, 11] (see Sect. 3.1). Moreover, this quantity has been assessed by the authors within preliminary tests as effective for pushing strength properties on M10-level after the standardized testing date of 28 days [12].

The frost-thaw cycle resistance tests (oriented on $[13,14])$ were operated on standardized samples in the laboratory. The compressive strength comparison was assessed as suitable indicator to quantify the potential internal deterioration of mortar structures within a previous study by the authors $[15,16]$. Moreover, it is the most commonly used value for the representation of mechanical strength in several publications (e.g. $[2,6])$ and the parameter on which the classification is basically oriented [10, 12]. Therefore, each sample, aged for a varying period, was assessed by measuring the compressive strength value before (or without) conducting the frost-thaw load and comparing it with 
the strengths obtained after running the durability experiments.

Parallel to this, we worked with three-stone test specimen as recommended by [17] as a "hybrid" testing series between the lab study and in-the-fieldapplications. These compound samples (mortar and natural stones) were exposed to real weathering conditions in the winter season. Hence, we combined a standardized lab method with an applied testing series to a comparative setting of differently aged samples. The study was completed by the application of the materials on the historic ruin of Thaur [18] a few weeks before the first frost occurrence in order to validate the results of the previous trials in a real application field, taking into account the requirements of specific parts of a building.

\section{Research aim}

In summary, we intend to find responses to the following delicate questions:

- Is the use of Portland cement in NHL-based masonry mortars required or/and reasonable for the improvement of frost resistance?

- Until which period of time before the first occurrence of frost can the tested mortars be applied with a marginal risk to be damaged due to frost exposure?

- How is the interpretability of the lab study compared with the conditions on the building sites in the winter season? Are there any material specific effects of NHL-based mortar constitution that affect the resistance to frost load in early ages?

The aim of the present case study is to give recommendations for the using period of NHL-based masonry mortars in cultural heritage near the winter season and in cold and unpredictable climates, respectively. Furthermore, we intended to assess the potential addition of Portland cement for improving the early durability properties of the correspondent materials, in particular when inappropriate conditions like soaked walls have to be considered. This should provide findings that can be used to plan the application of both materials systematically in the field of restoration and cultural heritage, where the preservation of historical values and the long-term durability are the most important aspects.

\section{Materials and methods}

\subsection{Materials}

In order to consider the objective of the comparison of a pure NHL-based masonry mortar with a mixture modified with a small content of cementitious binder, we applied material $\mathrm{E}$ as base mixture, which was already incorporated in a previous study with a similar quality [16] (see Table 1). It contains NHL 5 (according to ÖNORM EN 459-1 [10]), produced out of shell limestone [19], its mineralogical constitution is given in Table 2. Additionally, we designed a second base mixture (material I, see Table 1) with an amount of

Table 1 (a) Gravimetric and (b) volumetric recipes (standardized on the NHL 5-amount) of the used mortar materials of the present study

\begin{tabular}{|c|c|c|c|c|c|c|c|}
\hline \multirow[t]{2}{*}{ Material } & \multicolumn{4}{|c|}{ (a) Raw material quantities [wt $\%$ ] } & \multicolumn{3}{|c|}{ (b) Raw material volume fractions } \\
\hline & NHL 5 & CEM I $52.5 \mathrm{R}$ & Aggregate $0-6 \mathrm{~mm}$ & Aggregate $4-16 \mathrm{~mm}$ & NHL 5 & CEM I $52.5 \mathrm{R}$ & Sum. Agg. 0-16 mm \\
\hline $\mathrm{E}$ & 11.5 & - & 88.5 & - & 1.0 & - & 2.8 \\
\hline I & 11.5 & 5.0 & 83.5 & - & 1.0 & 0.2 & 2.7 \\
\hline E $16 \mathrm{~mm}$ & 10.0 & - & 76.6 & 13.4 & 1.0 & - & 3.3 \\
\hline I $16 \mathrm{~mm}$ & 10.0 & 4.3 & 72.3 & 13.4 & 1.0 & 0.2 & 3.1 \\
\hline
\end{tabular}

Material E (already investigated within a former survey [16]) and material I have been used for the prismatic samples and the threestone specimen, the $16 \mathrm{~mm}$ versions for the testing areas at the ruin of Thaur. For the calculation of the volumetric ratios the following bulk densities were used: NHL 5: $550 \mathrm{~kg} / \mathrm{m}^{3}$, CEMI $52.5 \mathrm{R}: 1000 \mathrm{~kg} / \mathrm{m}^{3}$, Aggregate 0-6 mm: $1500 \mathrm{~kg} / \mathrm{m}^{3}, \mathrm{Aggregate}$ 4-16 mm: $1550 \mathrm{~kg} / \mathrm{m}^{3}$ 
Table 2 Mineralogical composition of the used NHL 5 and white Portland cement determined by XRD, (data of NHL 5 already published in [15] and [16]; Amount of components: *+++major, ++minor, +low, - traces

\begin{tabular}{lll}
\hline Phase & NHL 5 & CEM I 52.5 R \\
\hline Portlandite & +++ & n.d \\
$\beta$-dicalciumsilicate & ++ & ++ \\
Tricalciumsilicate & n.d & +++ \\
Calcite & + & + \\
Katoite & + & n.d \\
Tricalcium aluminate (orthorh.) & + & + \\
Gehlenite & + & n.d \\
Monocalcium aluminate & + & n.d \\
Magnesite & - & n.d \\
Periclase & - & n.d \\
Quartz & - & - \\
Rutile & n.d & n.d \\
Gypsum & n.d & + \\
Anhydrite & n.d & - \\
Bassanite & n.d & - \\
\hline
\end{tabular}

$5 \mathrm{wt} \%$ white Portland cement (CEM I $52.5 \mathrm{R}$ acc. to [20]) referred to total mortar weight (see Table 1), whose constitution is listed in Table 2 too. The selection of the cementitious binder and its addition amount based on the following motivations:

- White Portland cement becomes frequently used by craftsmen on building sites because it does not significantly modify the color of (bright) mortars. It is available in Austria as CEM I 52.5 R (acc. to [20]), which implies that this type very effectively improves the hydraulic hardening. Already quite small admixture quantities are sufficient to reach the desired effects.

- The chosen quantity of Portland cement admixture is similar to the amount of cement-admixtures that are used to improve the (early) mechanical properties of pure NHL-based mortars on building sites [8]. Additionally, the amount is oriented on two elder publications $[9,11]$ that aimed among others to improve the general durability of lime-based mortars with Portland cement additions. We used the bulk densities of corresponding raw material used within our project to calculate the gravimetric mixing ratios out of the volumetric ones presented in the primary literature. Accordingly, the quantity of $5 \mathrm{wt} \%$ (or 0.48 times the volume of the main binder NHL) is located slightly below the quantities assessed in the literature as suitable to improve the durability ([11]: 5.8-8.9 wt\%, [9]: $7.9 \mathrm{wt} \%$ ), where the specific cement type is not clearly stated.

- In fact, the cement admixture as realized within the study affects the binder composition as the binderto-aggregate ratio, which could lead to a modification of mortar workability. However, this procedure is similar to the building sites, where a "bucket forefront" of cement becomes added on top of a pre-mixture based on NHL, or a volumetric NHL-aggregate mixture [8]. During preliminary tests, it was ensured $\mathrm{s}$ that the amount used does not have a negative effect on the working performance.

The base mixtures contain natural sand as aggregate that contains miscellaneous, carbonic and crystalline components with a grading of $0-6 \mathrm{~mm}$ and an elevated degree of roundness. Both base mixtures were homogenized in the production plant of the project partner and were provided as $25 \mathrm{~kg}$ bagged cargo dry mortar. The obtained fresh mortar properties of the base mixtures material $\mathrm{E}$ and I are depicted in Table 3.

During preliminary trials, both base mixtures material $\mathrm{E}$ and $\mathrm{I}$ have been tested in order to be complemented by the addition of a coarse, local gravel (e.g. 4-8 or 4-16 $\mathrm{mm}$ ) to adapt the aggregate selection to the requirements of specific building objects. Those trials showed that the addition of 12.5 vol.- $\%$ of coarse aggregate (equates about $5 \mathrm{~L}$ per $50 \mathrm{~kg}=2$ bags of pre-mixture) does not significantly modify the relevant properties of the resulting hardened mortars. Hence, the concept to adapt the base mixtures with local gravel was executed when the masonry restoring at the ruin of Thaur was performed. Consequently, the craftsmen on the building site added an amount of $5 \mathrm{~L}$ of a well-rounded, local gravel with a grading of $4-16 \mathrm{~mm}\left(\rho \approx 1.55 \mathrm{~kg} / \mathrm{dm}^{3}\right)$ per bag of base mixture, which amounts $13.4 \mathrm{wt} \%$ or 0.48 volume fractions compared to the implied NHL 5 content (see Table 1). The components were mixed for at least 5 min with the compulsory mixer to a fresh masonry mortar with an adequate workability. The correspondent water demands and fresh mortar consistencies are illustrated in Table 3. 
Table 3 Fresh mortar properties of the used mortar materials of the present study

\begin{tabular}{lllll}
\hline Material & \multicolumn{5}{l}{ Fresh mortar properties } & & \\
\cline { 2 - 5 } & Water content [wt\%] & Initial flow diameter [mm] & Fresh mortar raw density [kg/dm $\left.{ }^{3}\right]$ & Air void content [vol.-\%] \\
\hline E & 13.0 & 154 & 2.24 & 4.0 \\
I & 14.0 & 158 & 2.21 & 5.0 \\
E $16 \mathrm{~mm}$ & 16.8 & 163 & - & - \\
I $16 \mathrm{~mm}$ & 17.4 & 172 & - & - \\
\hline
\end{tabular}

\subsection{Methods}

The experimental program of this study compares a pure NHL-based masonry mortar (material E) to one that has been enriched with Portland cement (material I). Their relevant properties like the development of mechanical strength, the water transport behavior and the frost-thaw durability in early ages were studied in the laboratory. For that, we used prisms according to the testing standard for the determination of flexural and compressive strength of hardened mortar ÖNORM EN 1015-11 [21]. This also enables the results to be confronted with references from the literature, which are often based on the compressive strength as guide value for the mechanical stability of corresponding materials $[12,22]$. The so-obtained findings were compared with the results of parallel outdoor exposure of three-stone specimen, built up according to the sample arrangement presented in the testing standard for masonry ÖNORM EN 1052-2 [14] (for the parallel outdoor exposure). Moreover, the mortars were used to build test walls near the historic ruin of Thaur in Tyrol to estimate their usability in a real application, a common technique that is often used by restorers (described e.g. in [23]). An overview of the conducted methods that are strongly interrelated and support each other's significance is given in Fig. 1.

The fresh mortar mixtures, which have been used to prepare the sample prisms and the three-stone specimen, were produced in a laboratory mixer according to actual cement standardization ÖNORM EN 196-1 [24], using a total mixing time of $1 \mathrm{~min}$ (see [15]). The consolidation of the prisms was conducted by "jolting" oriented on the jolting table method, where the removal of air bubbles out of the fresh mortar occurs by beating the prism molds on a hard substrate as described in the testing standard for mortar flexural and compressive strength ÖNORM EN 1015-11 [24]. The consistency was measured by the flow table (initial flow diameter) following the procedure of the corresponding standard ÖNORM EN 1015-3 [25]. Additionally, the obtained fresh mortar raw density and air void content according to the related standards for mortar testing $[26,27]$ were determined. The production of test samples (three prisms with the dimensions160 $\mathrm{mm} \times 40 \mathrm{~mm} \times 40 \mathrm{~mm}$ acc. to [21] and one three-stone-specimen acc. to. [28] of each material and testing date) was planned in order to provide samples of 14, 28, 42 and 56 days of age. The sets of specimen were produced at intervals of two weeks in order to reach an overall testing date. So all mechanical properties could be determined on this single date and the testing series (the determination of the porosity, water transport and frost-thaw tests) could be started simultaneously. The mentioned samples were cured for the first 7 days at high humidity (relative humidity "RH" of $>95 \%$ ) and $20 \pm 2{ }^{\circ} \mathrm{C}$, whereat the prisms were demoulded after 5 days. The further sample conditioning up to the testing date occurred under $65 \pm 5 \% \mathrm{RH}$ and $20 \pm 2{ }^{\circ} \mathrm{C}$, provided by a climatic chamber. Moreover, on the first fabrication date, we produced an additional set of samples (three prisms and one three-stone-specimen) as fully carbonated set ("FC"-samples). After 28 days of standardized curing, these samples were carbonated in an accelerated setting by considering the findings published in [3]. Hence, we worked with a $\mathrm{CO}_{2^{-}}$ atmosphere of a concentration of $5 \%$ by volume, a relative humidity of $65 \pm 5 \%$ and a temperature of $20 \pm 2{ }^{\circ} \mathrm{C}$ (oriented on standard conditions, see ÖNORM EN 1015-11 [21]). The mentioned parameters were kept constant for another 28 days, thus reaching a total curing time of 56 days.

The first prismatic sample of each material and testing date was used for the determination of the 


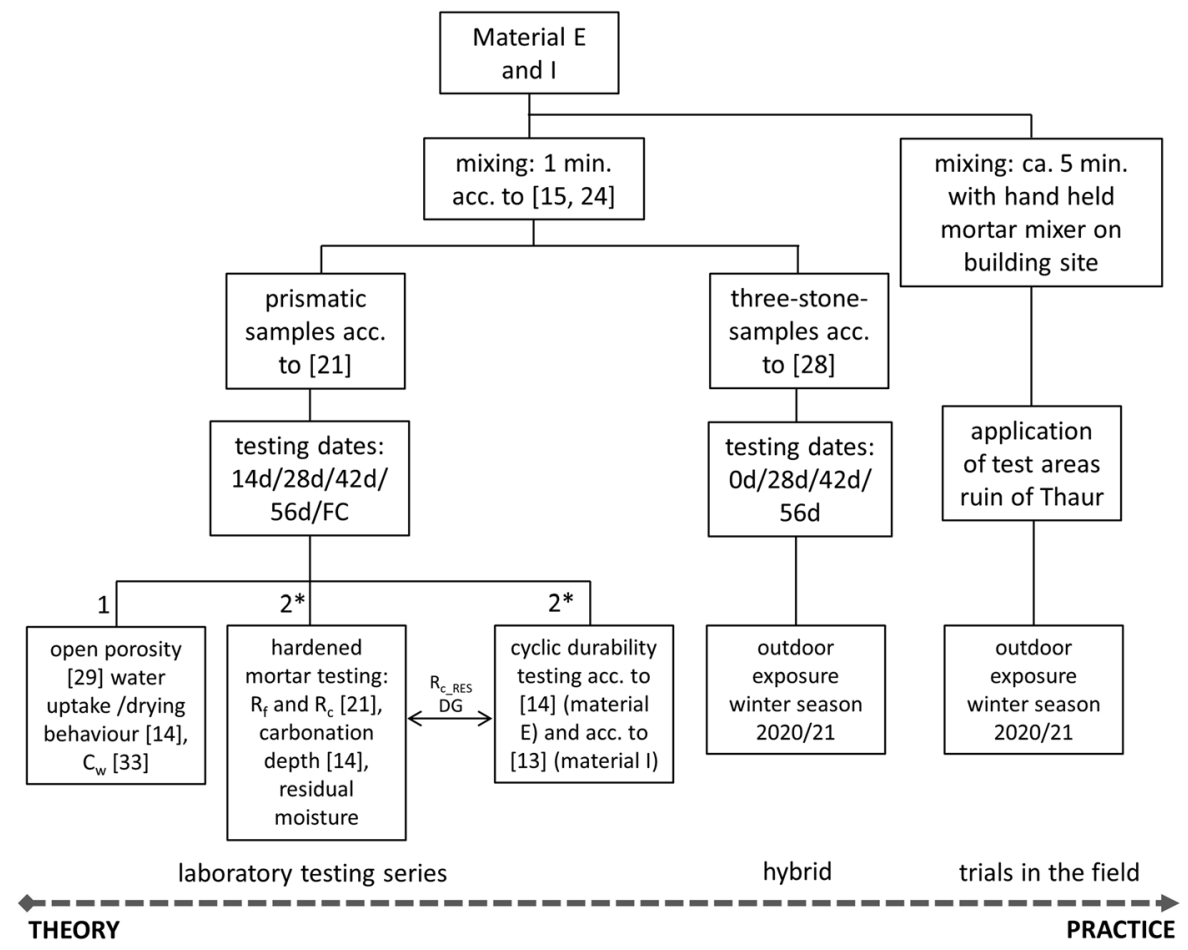

Fig. 1 Overview over the testing program executed within this study. 2*: Two prismatic samples of material $\mathrm{E}$ used for repetition of durability testing (method according to [14]) due to

hardened mortar properties that were conducted according to [21], thus through flexural $\left(R_{\mathrm{f}}\right)$ and compressive strength $\left(R_{\mathrm{c}}\right)$ measurements. Between the two tests, the carbonation depth (conversion of portlandite $\left(\mathrm{Ca}(\mathrm{OH})_{2}\right)$ to calcite $\left.\left(\mathrm{CaCO}_{3}\right)\right)$ was determined by phenolphthalein staining [14]. The remaining water content at the specific ages was measured by drying the residual material under $105{ }^{\circ} \mathrm{C}$ and calculating the percental weight loss. A survey over the applied fresh and hardened mortar testing methods, symbols, terms and definitions is given in Table 4.

The second prismatic sample was used to determine the open porosity (oriented on the hydrostatic weighting method for the determination of the porosity of natural stone [29]) and the water transport behavior. Subsequently, the water uptake under atmospheric pressure and the drying behavior were measured as described in a standard work for mortars for cultural heritage purposes [14]. Moreover, the capillary water absorption was determined using the standardized procedure [33]. Due to fast water uptake, the measuring interval was set on 10 min each until saturation. The capillary absorption coefficient $\mathrm{C}_{\mathrm{w}}$ was calculated integrated destruction when working with method according to [13]. Abbreviation "FC" stands for "fully carbonated" samples

by using the time interval between 10 and $30 \mathrm{~min}$. The so-obtained data were used to calculate key parameters (see Table 4), first reported in a previous study [15], to prove their suitability for benchmarking the durability. Thereby, possible correlations of characteristic values describing the porosity and water transport behavior were related to the results of cyclic frost-thaw testing. The results of those measurements were used to determine key parameters for durability prediction according to a former publication of the authors [15]. The calculated parameters are the open porosity, the saturation coefficient $S$ [30-32], the residual water content after $72 \mathrm{~h}$ of standardized drying $\mathrm{RW}_{72}$ and the capillary coefficient $\mathrm{C}_{\mathrm{w}}$ [33]. They were used to interpret the results of durability tests and to improve the reliability of the systematic application of the materials in ruin restoration.

The third sample prism was used for the assessment of frost-thaw durability of each sample age and recipe by means of exposing them to a cyclic test program (see Table 5 and Fig. 2). All samples were dried at $105{ }^{\circ} \mathrm{C}$ before the beginning of the durability testing series. Taking into account the approach of a previous 
Table 4 List of sample preparation and testing program methods (excluding cyclic test methods "CT", see Table 5) and corresponding abbreviations, symbols and (key) parameters and their references. Modified after $[15,16]$

\begin{tabular}{|c|c|c|c|}
\hline \multicolumn{2}{|c|}{ Operation/method for } & Description & References \\
\hline \multicolumn{2}{|c|}{ Sample preparation } & Preparation of sample prisms & [21] \\
\hline \multicolumn{2}{|l|}{ Mortar mixing } & Mixing method for preparation of the fresh mortar & {$[15,24]$} \\
\hline \multicolumn{2}{|l|}{ Sample curing } & Curing conditions & [21] \\
\hline \multicolumn{2}{|c|}{ Fresh mortar properties } & WF, IFD & {$[25]$} \\
\hline \multicolumn{2}{|c|}{ Carbonation conditions } & Conditions in the carbonation box & {$[3]$} \\
\hline \multicolumn{2}{|c|}{ Phenolphtalein test } & Test for the proof of carbonation progress & [14] \\
\hline \multicolumn{2}{|c|}{ Mechanical properties } & $\mathrm{R}_{\mathrm{f}}$ and $\mathrm{R}_{\mathrm{c}}$ determination & {$[21]$} \\
\hline Symbol & Unit & Description & References \\
\hline WF & {$[\mathrm{wt} \%]$} & Gauging water content (factor) & [25] \\
\hline IFD & {$[\mathrm{mm}]$} & Initial flow diameter (spread, consistency) & {$[25]$} \\
\hline$\rho_{\mathrm{m}}$ & {$\left[\mathrm{kg} / \mathrm{dm}^{3}\right]$} & Fresh mortar raw density & {$[26]$} \\
\hline $\mathrm{L}$ & [vol.-\%] & Air void content & {$[27]$} \\
\hline$\rho$ & {$\left[\mathrm{kg} / \mathrm{dm}^{3}\right]$} & Raw density & {$[-]$} \\
\hline $\mathrm{C}_{\mathrm{d}}$ & {$[\mathrm{mm}]$} & Mean carbonation depth & {$[15]$} \\
\hline $\mathrm{RM}$ & {$[\mathrm{wt} \%]$} & Residual moisture content & {$[15]$} \\
\hline $\mathrm{R}_{\mathrm{f}}$ & {$\left[\mathrm{N} / \mathrm{mm}^{2}\right]$} & Bending tensile (flexural) strength & {$[21]$} \\
\hline $\mathrm{R}_{\mathrm{c}}$ & {$\left[\mathrm{N} / \mathrm{mm}^{2}\right]$} & Compressive strength & {$[21]$} \\
\hline $\mathrm{R}_{\mathrm{c} \_ \text {RES }}$ & {$[\%]$} & Residual compressive strength & {$[15,16]$} \\
\hline DG & {$[\%]$} & Deterioration grade & {$[15,16]$} \\
\hline Key parameter & Unit & Description & References \\
\hline $\mathrm{OP}$ & [vol.-\%] & Open porosity: total open pore space & [29] \\
\hline $\mathrm{S}$ & {$[\%]$} & Saturation coefficient & {$[30-32]$} \\
\hline $\mathrm{RW}_{72}$ & {$[\mathrm{wt} \%]$} & Remaining water content after $72 \mathrm{~h}$ of drying & [15] \\
\hline $\mathrm{C}_{\mathrm{w}}$ & {$\left[\mathrm{kg} /\left(\mathrm{m}^{2} / \mathrm{l}\right.\right.$} & Water absorption coefficient & [33] \\
\hline
\end{tabular}

case study [16], we chose a dynamic testing setup and the corresponding frost-thaw cycle presented by [13] in reference to the dynamic application field at the building site (see below). Due to the assumption that a recently built up masonry part of a historical building and its juvenile mortar becomes widely protected from de-icing salt in early ages, we used pure tap water instead of a NaCl-solution (as indicated in the literature [13]) for the testing. The described method led to good comparability of the data of material I, but also to an extensive destruction of all not fully carbonated samples $(14 \mathrm{~d}, 28 \mathrm{~d}, 42 \mathrm{~d}, 56 \mathrm{~d})$ of pure NHL-based material E. Given that lack of possibility to assess the impact of the operated method quantitatively, we decided to repeat the sample production for material $\mathrm{E}$ and the running of frost-thaw cycles using a varying sample preparation method for the durability testing cycles. According to this, the samples were saturated in tap water and wrapped into a plastic foil, forming a static setup/closed system according to [14], instead of testing them directly in the water according to [13] (dynamic setup/open system) (see Fig. 2). The sample preparation method by using sealed prisms was also used by other authors for durability testing [34]. The corresponding hardened mortar testing was repeated too. Therefore, the prisms were wrapped into a LDPE (low density polyethylene) plastic foil after saturating them with tap water after the curing periods [14]. The operating with this softer, static durability testing method allowed the quantitative assessment of its influence on sample deterioration. For both materials and their according specific sample preparation method we used the frost thaw cycle provided by [13] with a duration of $22 \mathrm{~h}$, a temperature range of $-20{ }^{\circ} \mathrm{C}$ to $+20{ }^{\circ} \mathrm{C}$ and an iteration of 20 times (see Table $5 b$ ). 
(a)

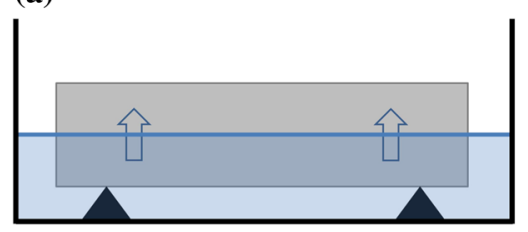

(b)

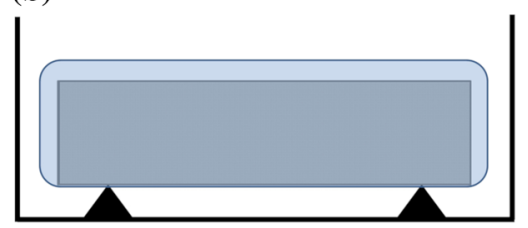

Fig. 2 Schematic drawing of the used test setup in the course of this study. a sample prism in tap water according to [13] - dynamic setup (open system), b saturated and sealed/wrapped sample prism according to [14]—static setup (closed system); modified after [16]

Table 5 (a) List of the used cyclic testing methods in the present study;

(b) Sequential arrangement of frost-thaw cycle $\mathrm{C}_{\mathrm{A}}$ according to [13] and [16]

*Relative humidity of $30 \%$ required according to [13]

\begin{tabular}{llll}
\hline a) Material & Test setup [16]/ reference & Frost-thaw cycle & Solution \\
\hline E & CT1, dynamic setup, [13] & $\mathrm{C}_{\mathrm{A}}$ acc. to [13, 16] & Pure tap water \\
I & CT3, static setup, [14] & $\mathrm{C}_{\mathrm{A}}$ acc. to [13, 16] & Pure tap water
\end{tabular}

\begin{tabular}{llll}
\hline (b) Step no & Time interval $[\mathrm{h}]$ & Starting temperature $\left[{ }^{\circ} \mathrm{C}\right]$ & Target temperature $\left[{ }^{\circ} \mathrm{C}\right]$ \\
\hline 1 & $0-5$ & $+20.0^{*}$ & -4.0 \\
2 & $5-12$ & -4.0 & -18.5 \\
3 & $12-16$ & -18.5 & -20.0 \\
4 & $16-18$ & -20.0 & -1.0 \\
5 & $18-22$ & -1.0 & $+20.0^{*}$ \\
\hline
\end{tabular}

The evaluation of the impact of the operated durability testing series was characterized by testing compressive strength after the cyclic tests $R_{\mathrm{c}_{-} \mathrm{CT}}$., giving an estimation about the residual internal stability of the sample prisms. It was referred to the former compressive strength $R_{\mathrm{c}}$ in order to calculate the percentage of residual strength $R_{\mathrm{c} \_ \text {RES }}$ [\%] $\left(=R_{\mathrm{c} \_\mathrm{CT}} * 100 \% / R_{\mathrm{c}}\right)$ and the deterioration grade DG $[\%]\left(=100 \%-R_{\mathrm{c} \_ \text {RES }}\right)$ (same method as used in [16]; see also Table 4).

Parallel to the prismatic samples, we built up threestone specimen out of Triassic alpine shell limestone [35] and our fresh mortars. The related standard [28] provides a sample arrangement of stones and mortar primarily for flexural strength determination, which can be also used as composite specimen (see Fig. 3a), outlined as ideal configuration for an applied durability assessment [17, 32]. Afterwards, we exposed them to the cold temperatures of the winter season 2019/20 in a comparative setting. Three stones with natural, miscellaneous shapes (dimensions of $20-30 \mathrm{~cm} \times$ $10-20 \mathrm{~cm} \times 5-15 \mathrm{~cm}$ ) were used to construct one specimen per mortar recipe and testing date with a nearly constant joint thickness of about $10-20 \mathrm{~mm}$. Following a curing period of 14, 28, 42 and 56 days at
$65 \pm 5 \% \mathrm{RH}$ and $20 \pm 2{ }^{\circ} \mathrm{C}$ the samples have been exposed to winterly outdoor temperatures, covered by a roof, in the Alpine region (Innsbruck, Tyrol, Austria, $574 \mathrm{~m}$ a.s.l.; see Fig. 4a [36]). For the testing series with the three-stone specimen, we provided a freshly built up sample too, which has been exposed to weathering conditions directly after building it up on $30^{\text {th }}$ January 2020. It was not possible to provide a fully carbonated sample because of the dimensions of this specimen type and the carbonation box, respectively. To simulate a periodical precipitation (or general: water feeding) event, the specimen were wetted by submerging them for 10-15 s into a room tempered water reservoir. That procedure has been repeated periodically every two weeks.

The impact of weathering exposure has been evaluated by observing potential damaging, cracks and surface flaking by visual means. Additionally, the flaked material of the mortar joints was comparatively weighted after passing the frost period in May.

The final part of the present study was the application of both mixtures to restore a small sector of an ancient defence building, following the application principles of natural ashlar masonry described in [37] (see Fig. 3b,c). Today it is preserved as relicts of a 

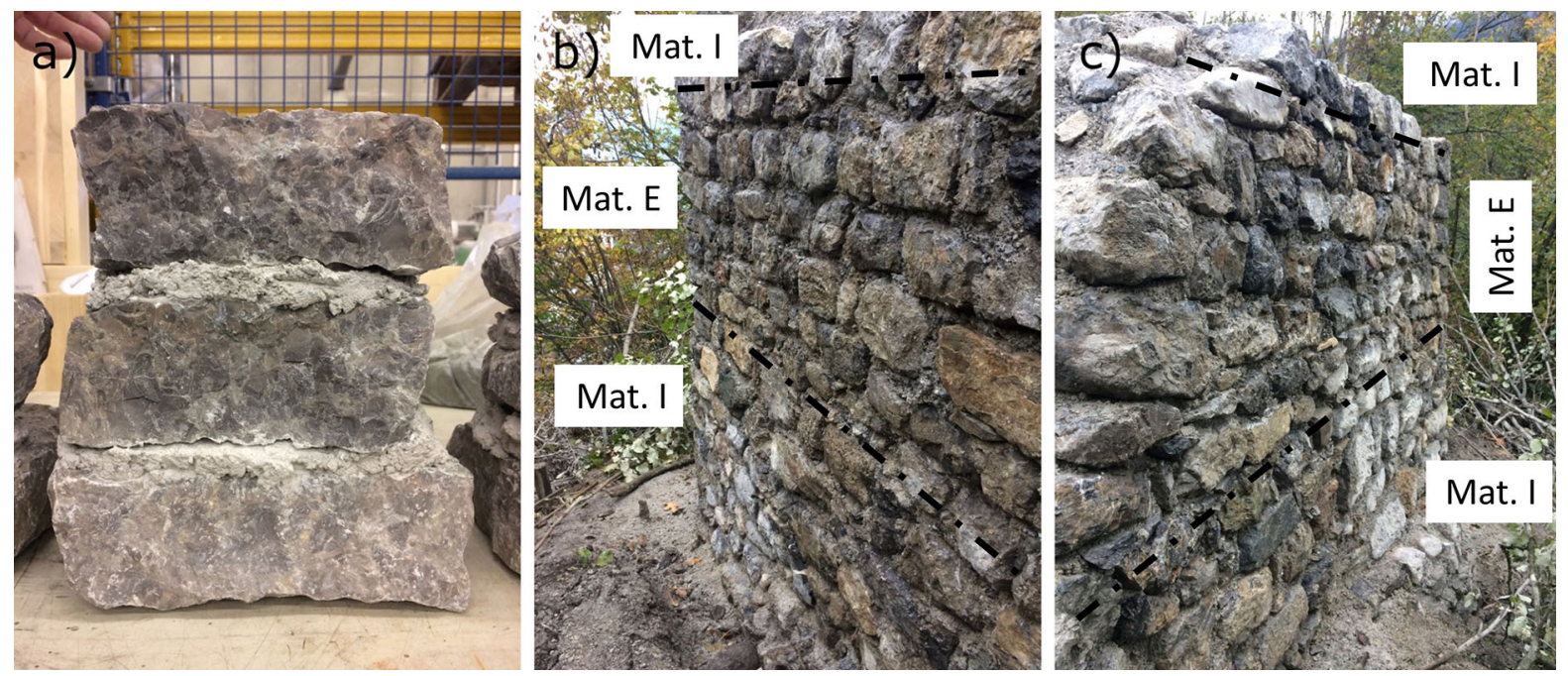

Fig. 3 a Three-stone specimen oriented on [28] of material E before the exposing (width of undermost stone: $26 \mathrm{~cm}$. b N-exposed and c E-exposed wall sector on the ruin of Thaur directly after the restoration (15th October 2020)

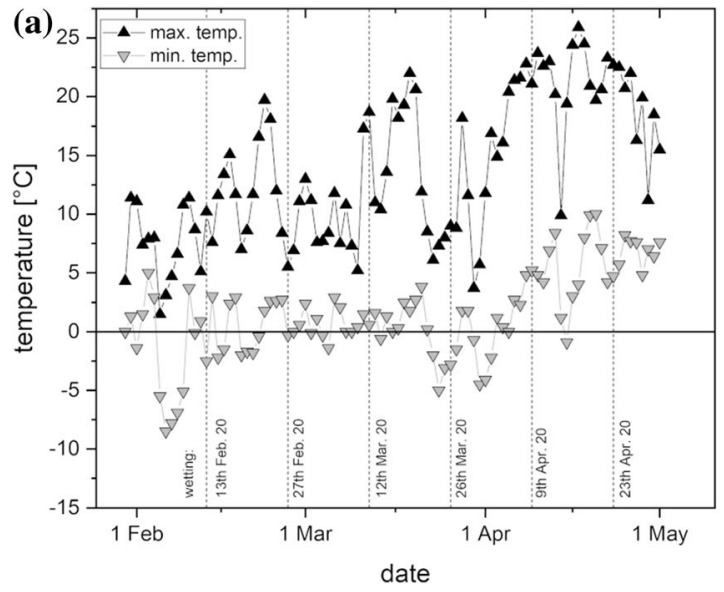

Fig. 4 a Outdoor temperature (daily maxima and minima) during the exposure period in the winter and spring season 2020, wetting dates are depicted as dotted lines; b Outdoor temperature (daily maxima and minima) and precipitation during the

side wall near the historic castle of Thaur (Tyrol, Austria; ca. $7 \mathrm{~km}$ east of Innsbruck; ca. $800 \mathrm{~m}$ a.s.1.), which was constructed from around 1200 and is preserved in a ruinous state nowadays [38]. The refurbished sectors have a width of $3.4 \mathrm{~m}$ and $3.8 \mathrm{~m}$, a height of about $2.0-2.5 \mathrm{~m}$ in direction of their exposure to North and East. The diameter of the wall is about $0.8 \mathrm{~m}$, the volume behind the walls is filled up with ground earth up to about $0.5 \mathrm{~m}$ below the upper edge (see Fig. 5). According to these framework conditions a high rising damp load inside the wall, a

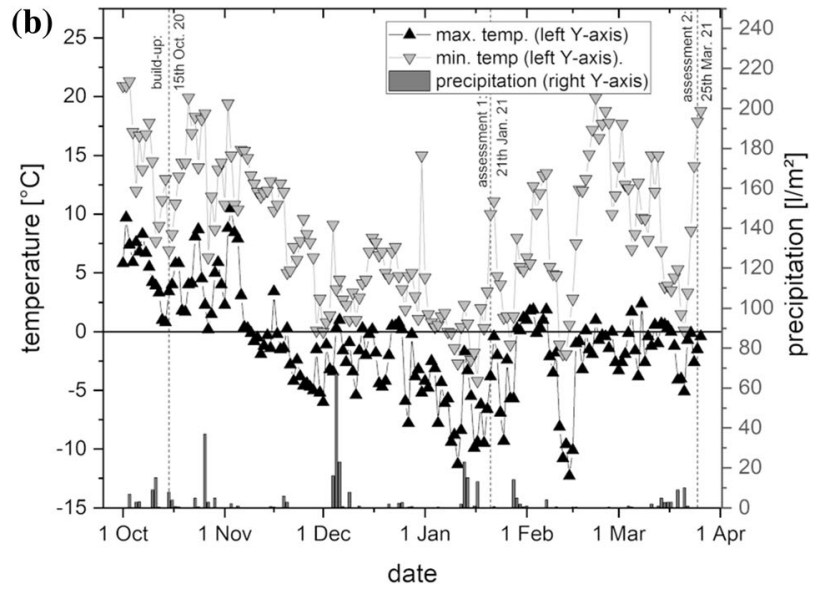

first months after the build-up of the sample areas at the ruin of Thaur (winter season 2020/21). Data provided by [36] and [39]

hindered $\mathrm{CO}_{2}$-intrusion and therefore an elevated risk of frost-thaw-processes especially at the East-exposed wall is supposable as inconvenient factor for the durability of the used mortars. We applied the base mixture with Portland cement (material I) at the base of the wall to block additional rising damp and to provide a general stability. The material was used in addition on the crown of the wall to protect it from precipitation. In between, the pure NHL 5-mixture material $\mathrm{E}$ was used to allow an ample dewatering of the wall and of the backfilling material. For the 


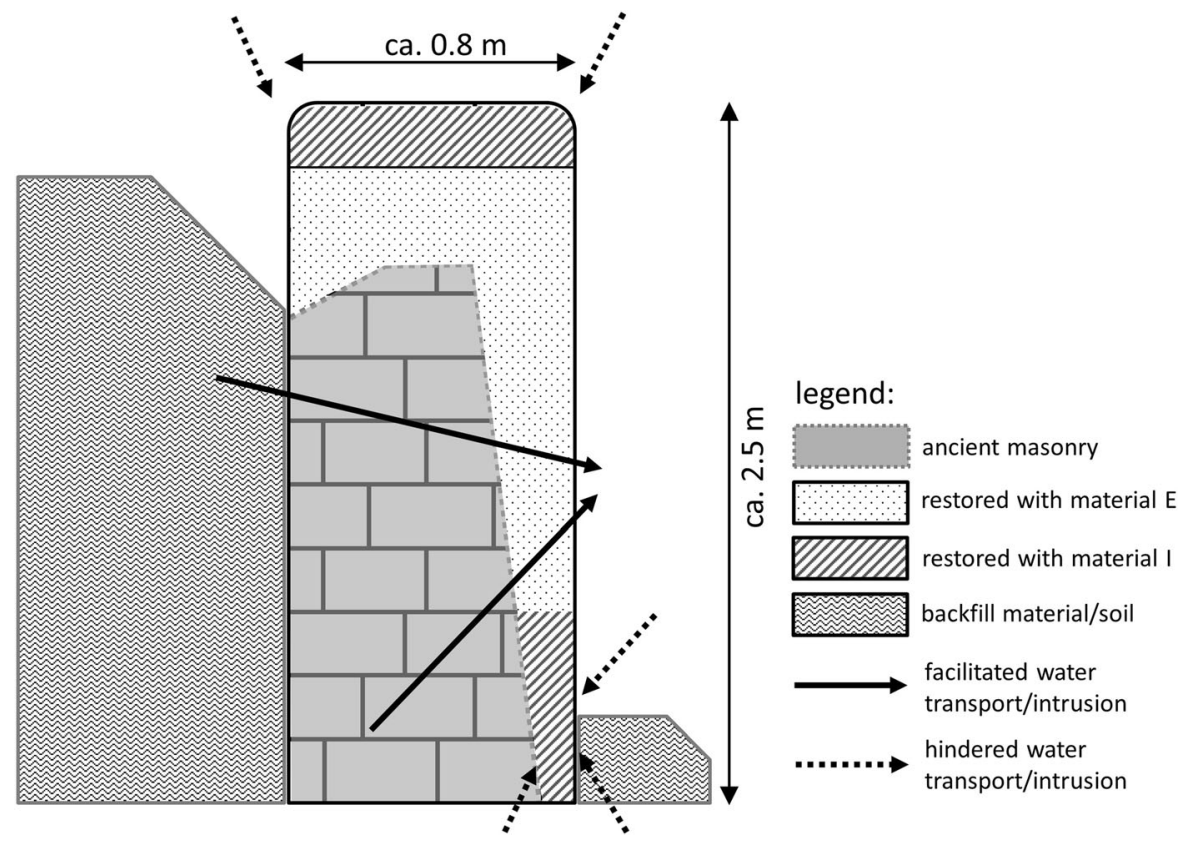

Fig. 5 Schematic drawing of the conceptual arrangement of the two mixtures during the restoration of the wall at the historic ruin of Thaur. The approach should facilitate the dewatering of the backfilling material and the remnant of the historic wall. The

construction process, which took place from 5 to 15 th October 2020 (see Fig. 4b [39]), local natural Triassic carbonate quarrystones and pinnings of the surrounding areas (formerly part of the castle masonry) were used. The mortars were designed as masonry mortar with specific admixtures of a local, coarse gravel (grain size 4-16 mm) and were mixed by a hand-held mixer (Type Collomix, paddle type WK; mixing for ca. $5 \mathrm{~min}$ ). The specific composition and water content is given in Tables 1 and 3. The ashlars were placed and jointed in one work process, thus with the same mortar for both work steps. After one day, the joints were scratched with a wire brush and washed with a soft water jet to open the surface. That removal of the upper layer uncovered the aggregates and adumbrates an apparent weathering stage.

The application occurred only a few weeks before the first frost in order to assure a distinct frost load within the first months after bricking up the wall. Therefore, the straining affected the almost fresh and presumably only superficially carbonated mortars. The assessment of the test areas has already been made about three months after the construction and after five and a half months, thus after the winter period. Analog intrusion of precipitation water and capillary rising damp is prevented by the use of the denser material I at the crown and at the bottom of the wall

to the three-stone specimen we evaluated the areas by observing potential damaging, cracks and surface flaking of the mortar joints.

\section{Results and discussion}

\subsection{Prismatic samples (laboratory testing)}

The testing of the mechanical properties, conducted on the prismatic samples, reveals an overview about the strength development within the first weeks of both materials in relation to their composition and age (Fig. 6 and Table 6). NHL-based mortars have a dual hardening process that is affected by hydraulic reaction and the carbonation of portlandite to calcite. Both are triggered by the moisture content [3], which itself depends from the mixing conditions and the time period. Hence, the obtained results are linked to the curing conditions and have to be reconsidered in regards to variable conditions on the building sites (e.g. at the sample areas in the ruins of Thaur castle).

Observing the standarized prismatic samples, material $\mathrm{E}$ shows a nearly constant compressive 


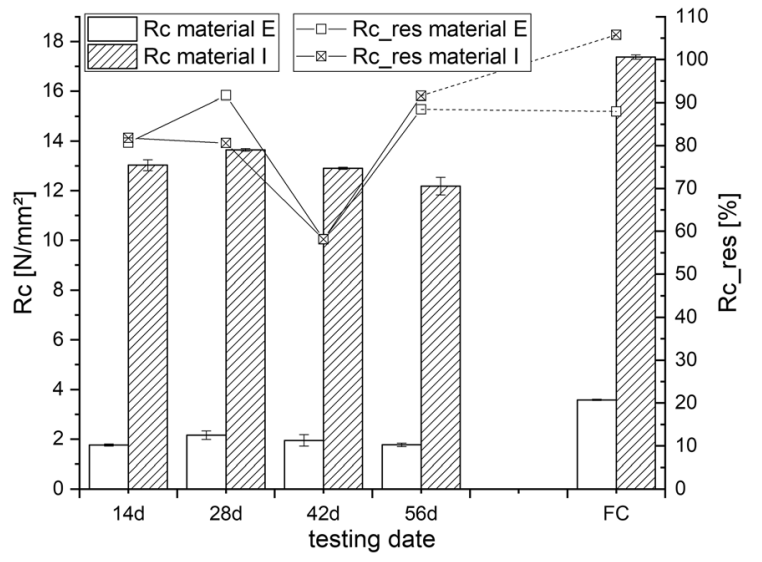

Fig. 6 Chronological compressive strength $R_{\mathrm{c}}$ development for both materials $\mathrm{E}$ and I (left y-axis) and residual compressive strength $R_{\text {c_res }}$ (right y-axis) in course of time for the prismatic, standardized cured samples

strength of ca. $2 \mathrm{~N} / \mathrm{mm}^{2}$ from 14 days on to 56 days of curing, which is attributed supposably to hydraulic reaction and to first carbonation onset. The considerable contribution of carbonation to hardening of the

Table 6 (a) Hardened mortar properties and results of the cyclic testing methods $\left({ }^{*} \mathrm{R}_{\mathrm{c} \_ \text {res }}\right.$ and DG: material $\mathrm{E}$ tested according to [14], material I according to [13]) of the different pure NHL-mortar is apparent when the compressive strength of the fully carbonated samples is observed: it reaches ca. $3.6 \mathrm{~N} / \mathrm{mm}^{2}$ and therefore almost two times the value before broad carbonation occurrs. In contrast, the strength properties of material I are highly affected by the reaction of tricalciumsilicate as main component of the Portland cement that leads to a compressive strength of about $13 \mathrm{~N} / \mathrm{mm}^{2}$ already after 14 days of curing. A compressive strength of ca. $5 \mathrm{~N} /$ $\mathrm{mm}^{2}$ is assessed to be an approximate value for a sufficient frost-thaw durability of young concrete [40]. The proportional fraction of the carbonation to strength enhancement is explicitly lower for material I compared to material E. It amounts about 1.3 times the strength before integrated carbonation, while the fully carbonated sample exhibits a compressive strength of ca. $17.4 \mathrm{~N} / \mathrm{mm}^{2}$. Both materials show a slight but noticeable decrease of strength after 28 days (42 and 56 days values). If this observation is an artifact of sample measurement scattering or a contribution of carbonation accompanied by transformation processes of $\mathrm{CSH}$ phases could not be fully aged samples. (b) Gravimetric material loss (ML) of 3-stone specimen after the winter season

\begin{tabular}{|c|c|c|c|c|c|c|c|c|c|c|}
\hline \multirow[t]{2}{*}{ (a) } & \multicolumn{5}{|c|}{ Material E } & \multicolumn{5}{|c|}{ Material I } \\
\hline & $14 d$ & $28 \mathrm{~d}$ & $42 d$ & $56 \mathrm{~d}$ & $\mathrm{FC}$ & $14 d$ & $28 \mathrm{~d}$ & $42 d$ & $56 \mathrm{~d}$ & $\mathrm{FC}$ \\
\hline$\rho\left[\mathrm{kg} / \mathrm{dm}^{3}\right]$ & 2.08 & 2.04 & 2.05 & 2.08 & 2.13 & 2.10 & 2.03 & 2.08 & 2.08 & 2.12 \\
\hline $\mathrm{C}_{\mathrm{d}}[\mathrm{mm}]$ & 2.5 & 3.3 & 4.0 & 5.3 & $\begin{array}{l}20 \\
(100 \%)\end{array}$ & 0.8 & 1.8 & 2.8 & 3.8 & $\begin{array}{l}20 \\
(100 \%)\end{array}$ \\
\hline $\mathrm{RM}[\mathrm{wt} \%]$ & 0.68 & 0.61 & 0.59 & 0.57 & 0.59 & 2.61 & 2.07 & 1.96 & 1.81 & 1.13 \\
\hline $\mathrm{R}_{\mathrm{f}}\left[\mathrm{N} / \mathrm{mm}^{2}\right]$ & 0.6 & 0.7 & 0.9 & 1.0 & 1.0 & 2.9 & 3.7 & 3.4 & 3.2 & 4.1 \\
\hline $\begin{array}{l}\mathrm{R}_{\mathrm{c}}\left[\mathrm{N} / \mathrm{mm}^{2}\right] \\
\quad(\mathrm{SD})\end{array}$ & $\begin{array}{l}1.8 \\
(0.04)\end{array}$ & $\begin{array}{l}2.2 \\
\quad(0.17)\end{array}$ & $\begin{array}{l}1.9 \\
(0.23)\end{array}$ & $\begin{array}{l}1.8 \\
(0.07)\end{array}$ & $\begin{array}{l}3.6 \\
(0.03)\end{array}$ & $\begin{array}{l}13.0 \\
(0.22)\end{array}$ & $\begin{array}{l}13.7 \\
(0.06)\end{array}$ & $\begin{array}{l}12.9 \\
(0.04)\end{array}$ & $\begin{array}{l}12.2 \\
(0.35)\end{array}$ & $\begin{array}{l}17.4 \\
(0.09)\end{array}$ \\
\hline $\mathrm{R}_{\mathrm{c} \_ \text {RES }}[\%]^{*}$ & 80.6 & 91.8 & 58.2 & 88.5 & 88.0 & 81.8 & 80.6 & 58.1 & 91.5 & 105.8 \\
\hline DG $[\%]^{*}$ & 19.4 & 8.2 & 41.8 & 11.5 & 12.0 & 18.2 & 19.4 & 41.9 & 8.5 & -5.8 \\
\hline OP [vol.-\%] & 25.3 & 25.1 & 25.3 & 25.7 & 24.0 & 27.3 & 26.3 & 26.5 & 26.2 & 23.2 \\
\hline $\mathrm{S}[\%]$ & 89.7 & 89.6 & 89.0 & 87.6 & 87.8 & 87.7 & 86.5 & 86.6 & 86.6 & 85.3 \\
\hline $\mathrm{RW}_{72}[\mathrm{wt} \%]$ & 31.3 & 29.7 & 23.3 & 13.8 & 6.1 & 37.0 & 32.7 & 24.7 & 32.0 & 29.3 \\
\hline $\begin{array}{c}\mathrm{C}_{\mathrm{w}}\left[\mathrm{kg} /\left(\mathrm{m}^{2} /\right.\right. \\
\left.\left.\min ^{0.5}\right)\right]\end{array}$ & 2.1 & 2.0 & 1.8 & 2.2 & 2.0 & 0.7 & 0.6 & 0.9 & 0.9 & 0.8 \\
\hline \multirow[t]{2}{*}{ (b) } & \multicolumn{5}{|l|}{ Material E } & \multicolumn{5}{|c|}{ Material I } \\
\hline & Od & $14 d$ & $28 \mathrm{~d}$ & $24 d$ & $56 \mathrm{~d}$ & Od & $14 \mathrm{~d}$ & $28 \mathrm{~d}$ & $42 d$ & $56 \mathrm{~d}$ \\
\hline ML $[\mathrm{g}]$ & 34.1 & 6.0 & 4.1 & 4.7 & 4.3 & 11.4 & 4.9 & 1.6 & 1.6 & 3.6 \\
\hline
\end{tabular}


investigated. However, indications for the latter theory of the transformation of the products of hydraulic reaction by carbonation can be found in $[3,6,41]$ for comparable materials, thus with a moderate content of hydraulic components cured in similar conditions.

The impact of the frost-thaw durability tests, represented as residual (compressive) strength $R_{\mathrm{c} \_ \text {RES }}$ in Table 6 and Fig. 6, indicates an interesting effect observed for both materials: the relative impact of cyclic frost stress on the samples is most distinctive for the sample aged for 42 days. The effect can be explained by taking into account the curing conditions and the hydraulic components of the mortars. The young specimen (14 and $28 \mathrm{~d}$ ) show a moderate decrease of compressive strength through frost-thaw impact, but the remaining strength is still higher than for the sample aged for 42 days. In our opinion, this observation is explainable by two effects, which probably overlie and may both contribute to a minor damaging of those younger specimen:

(a) A reactivation of still unreacted, hydraulically active phases (primary $\mathrm{C}_{2} \mathrm{~S}$ due to slow reaction rate [42]) through the contact with water during the frost-thaw testing within the open pore structure, resulting in a "healing effect", which is also suggested in [43].

(b) We hypothesize a generally lower vulnerability to damaging through expansive ice crystallization due to a poor carbonation grade and therefore a softer, more flexible structure (deducible from results published in [41]).

The sample aged for 42 days instead reveals the highest deterioration grade and achieves a $R_{c \_R E S}$ of about $58 \%$ for both mortars. Therefore, it can be supposed that the hardened mortar structure is not yet developed as much as it can widely resist to stress induced through frost-thaw cycles. Additionally, the content of reactive hydraulic phases (or their accessibility by water) doesn't seem to be enough to heal the structure more substantially.

The samples aged for 56 days and the fully carbonated ("FC") samples just show a minor or no decrease of mechanical strength due to frost-thaw impact. Consequently, the correspondent curing time of at least 56 days is adequate to achieve a sufficient carbonation under the prevailing curing conditions, resulting in an ample stability and resistance against frost-thaw stresses. Also in the literature [41] the attaining of a certain equilibrium state after 56-90 days is mentioned in regard to the relevant properties of similar materials.

The key factors basically support the observed relationships and help to interpret the above mentioned findings (see Table 6a and [15]): the fully carbonated sample of material I shows, as well due to its Portland cement content, smaller capillary pores with a higher grade of complexity [44] and a slightly lower open porosity compared to material E. The smaller open porosity is related to the described higher compressive strength. The not fully carbonated samples instead don't follow this trend, probably because the pore space of material I is more voluminous (due to a higher primary water content), but even more affected by products of hydraulic reaction and therefore more stable than material $\mathrm{E}$.

The saturation coefficient $\mathrm{S}$ shows a slight decrease for both materials with the proceeding of the aging process. This assumes a better durability for older samples that show smaller values for $\mathrm{S}$ and therefore a higher empty pore space as a reserve for the expanding volume and stress of ice formation. Moreover, $\mathrm{S}$ is also following the general strength enhancement, but does not indicate the minor vulnerability of young specimen (14 and 28 days). This is explainable by the above mentioned processes, the healing effect and the softer structure in young samples. Those contribute over the whole frost-thaw stress to a lesser damaging grade, whereas the determination of $\mathrm{S}$ is a single measurement. Therefore, the functionality of $\mathrm{S}$ as key parametery for durability prediction is given under the constraint, when an adequate equlibrium state in regard to the hardening process is reached. Thus, a sufficient progress of hydraulic reaction and carbonation is necessary.

The residual water content $\mathrm{RW}_{72}$ as specific value for the drying behavior (see Table 6a) instead requires a differentiation between the two recipes: Observing material $\mathrm{E}$ reveals a constant decrease of residual water content, hence a faster dewatering with increasing age and carbonation grade. For the younger samples that are not yet fully carbonated the slower drying can possibly be explained by an effect described by [45]. The author states a certain transition resistance when water becomes transported over boundaries of two materials that both reveal a high capillary water transport, for example from the noncarbonated core of the samples to the already 
carbonated exterior. However, the drying behavior follows, comparable to the saturation coefficient $S$, the key parameters model for the samples of higher age (42 days and older). Those feature a certain equilibrium state regarding the hardening process (hydraulic reaction and carbonation). Generally, the drying rate of material I is slower in relation to material $\mathrm{E}$, which is a common observation when comparing NHL-based with Portland cement bearing materials $[2,16]$. Nevertheless, the 42 days-sample of material I exhibits the fastest drying rate (lowest residual water content $\mathrm{RW}_{72}$ ) and is also the one that shows the highest relative grade of deterioration during frost-thaw cycles. For the younger samples that presumably also show a higher relative durability, a certain reactivation of hydraulic phases, leading to a healing of the structure, can be assumed. The slower drying of the longer cured samples is possibly affected by the reaction products of hydraulic reaction and carbonation. Those are possibly forming a rigid sample body with a reduced porosity, where the water release is integratedly hindered. Thus, material I can be critical in regard to its drying function, especially when the exposure of the masonry allows high moisture release rates and a broad carbonation. Therefore, the enrichment of NHL-based mortars with Portland cement should be planned as carefully as the combination of different mortar recipes and their arrangement in regard to their application field.

The capillary absorption coefficient $\mathrm{C}_{\mathrm{w}}$ clearly reveals a higher capillary transport ability for the pure NHL-based mortar material E compared to the Portland cement bearing material I. This has already been observed by the authors [16] and is reported in the literature too [2]. However, we did not ascertain a significant variation or a systematic trend for the $\mathrm{C}_{\mathrm{w}}$ of differently aged samples. Nevertheless, former studies of the authors on similar, pure NHL-based materials revealed a tendency of higher $\mathrm{C}_{\mathrm{w}}$ values for younger, less carbonated samples ( 28 days aged) in relation to the fully carbonated ones $[15,46]$.

\subsection{Three-stone specimen}

The three-stone specimen of different ages $(0,14,28$, 42 and 56 days) that have been exposed to outdoor conditions should reveal the behavior of both materials under average weathering conditions. The periodical wetting of the specimen of different ages simulates repetitive precipitation events, which becomes overlaid by real natural influences like windy conditions, insolation and periods of natural frost occurrence (see Fig. 4a). Assessing the specimen after the frost period in May 2020 by visual means and by the gravimetric determination of material loss revealed unessential damaging induced through weathering for the samples older than 14 days (see Table $6 \mathrm{~b}$ ). The sample aged for 14 days of material I shows less damaging than the one of material E. That effect is even more pronounced for the fresh samples, where both materials showed a particular grade of damaging (still material $\mathrm{E}$ more than material I). Hence, the three-stone specimen can be correlated to the findings of the prismatic samples, where material I shows less susceptibility to damaging compared to material $\mathrm{E}$ at young ages. However, the effect of minimal durability after about 42 days could not be observed, probably because of the natural conditions leading to a time shift and a lower intensity of frost stresses at varying saturation grades and so forth.

\subsection{Application areas in the field}

The testing areas at the ruin of Thaur castle were passing through several intense frost periods, starting about four weeks after build-up and continuing after 5-6 weeks with decreasing temperature levels and fluctuating amplitudes over the whole winter season. The frost-thaw load expresses itself through substantial damaging of the pure NHL-based mortar material $\mathrm{E}$ (material loss in mortar joints of 1-2 cm; maximum up to $5 \mathrm{~cm}$ ) after an observation period of five and a half months (see Fig. 7b, c). The highest damaging grade is observable at the East-exposed wall, where an elevated intensity of frost-thaw load is expectable due to a higher thawing probability in winter season. Material I instead, reveals a sufficient resistance to frost-thaw impact. This is indicated through a slight sanding effect on the surface, but generally an adequate durability within the period under review can be observed (see Fig. 7b). Therefore, the results of the laboratory frost-thaw testing series on the prismatic samples appear as plausible under the consideration of the observed damaging at the test areas. They are indicating both a poor durability for material E before 56 days previous to the first intense frostthaw load. 


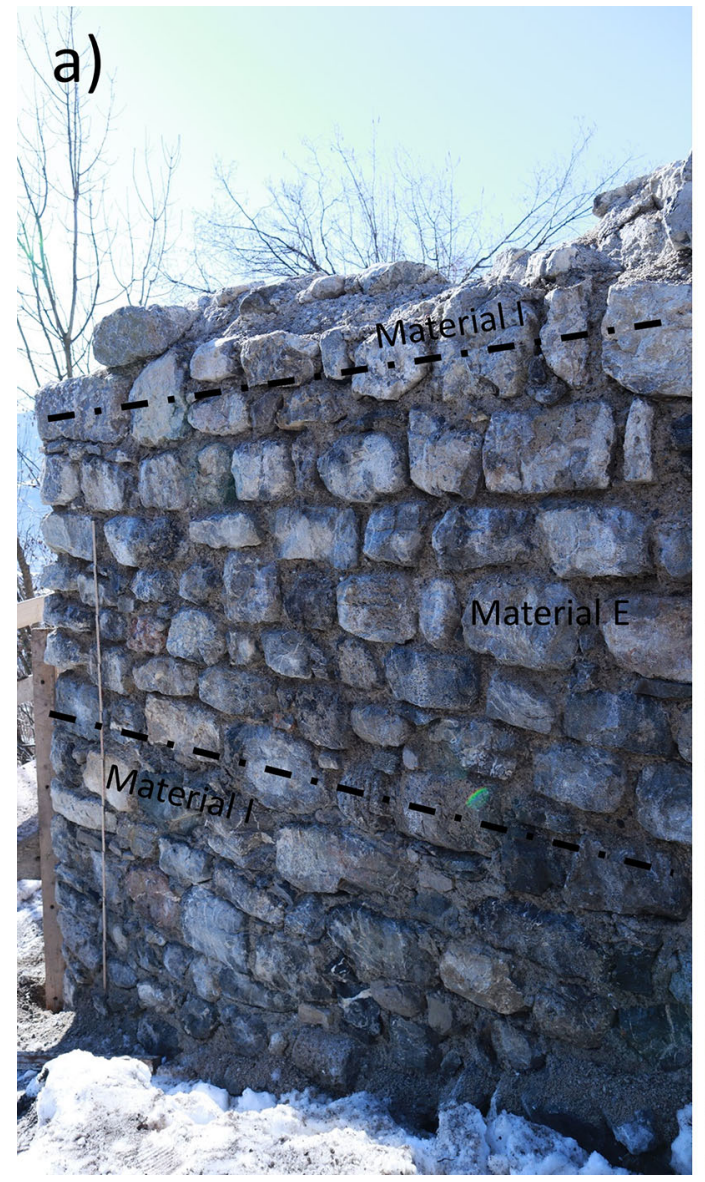

Fig. 7 Wall sector at the ruin of Thaur during and after the winter season. a $\mathrm{N}$-exposed wall with total height after reconstruction of about $2.5 \mathrm{~m}$ (see $2 \mathrm{~m}$ scale on the left) on 25th March. b detailed photo of material transition at the

\section{Conclusion}

Our study combined a laboratory testing series and applied approaches to obtain findings on the impact of Portland cement enrichements in NHL-based mortars on the early durability of the correspondent mortars. The use of standardized testing series and the work with applied test areas on the real surfaces allowed to relate theoretical, fundamental aspects to the practical behavior of the mortars.

Remarkably, we noted the potential of both mortars to anneal the structure if it becomes damaged within the first month, referred to standard-oriented curing conditions. Moreover, we observed the highest vulnerability, if first (intense) frost-thaw occurs after about 6 weeks, when a curing process comparable to
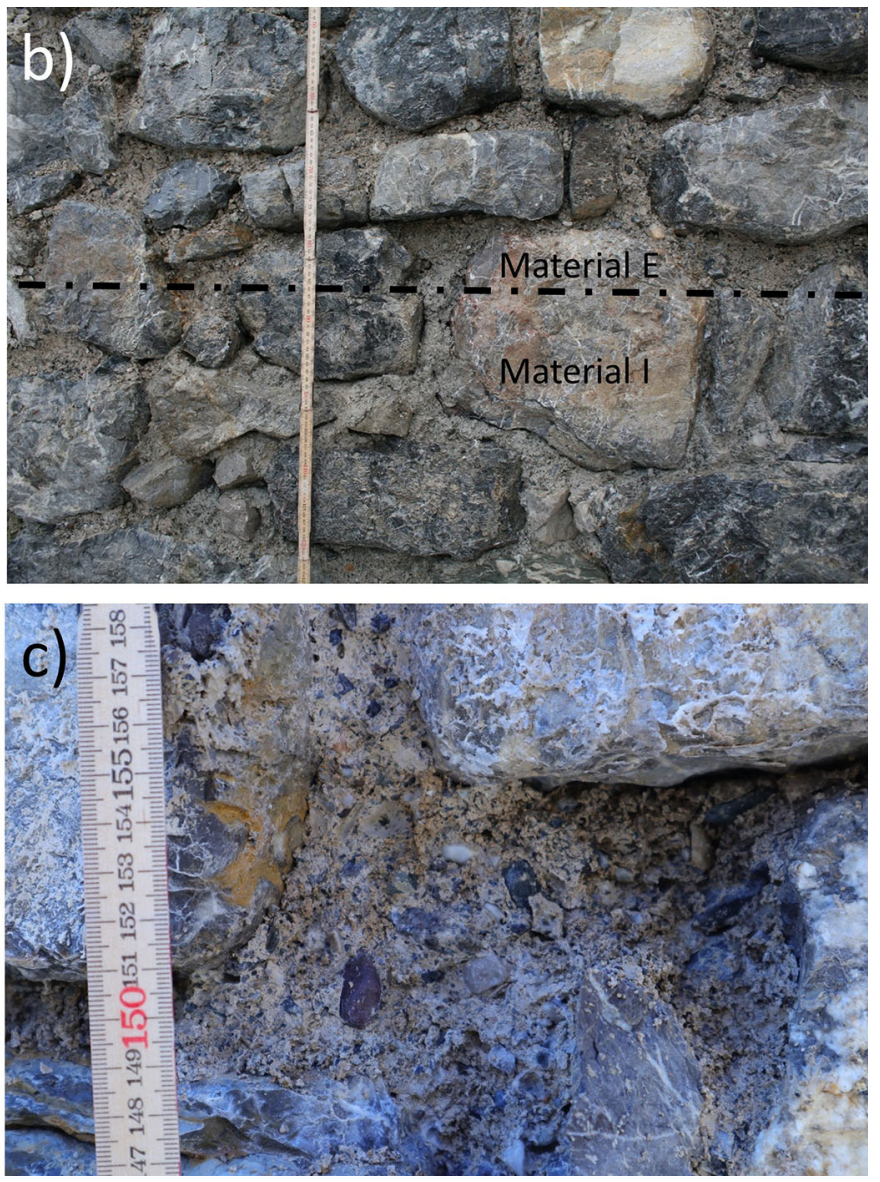

E-exposed wall reveals strong flaking in the joints of material $\mathrm{E}$ and non-significant deterioration for material I below (Foto: 21st January). c Intense surface flaking for material E on 25th March

the standarized one can be assumed. Therefore, we assess the use of the tested materials shortly before the winter season as highly risky for their durability and therefore it should generally be avoided. Instead, the occurrence of frosty nights within the first weeks after the application in spring, which cannot ultimately be excluded in alpine zones, is less risky due to the healing potential of the materials. The entirety of the related findings is illustrated in Fig. 8.

The study reveals in addition that the use of cement generally appears as convenient in regard to the obtained observations of cyclic testing in the laboratory and exposing the materials to real weathering conditions. An amount of about $5 \mathrm{wt} \%$ of Portland cement, which ranges in the lower region compared to the literature $[9,11]$, is definitely a sufficient quantity 


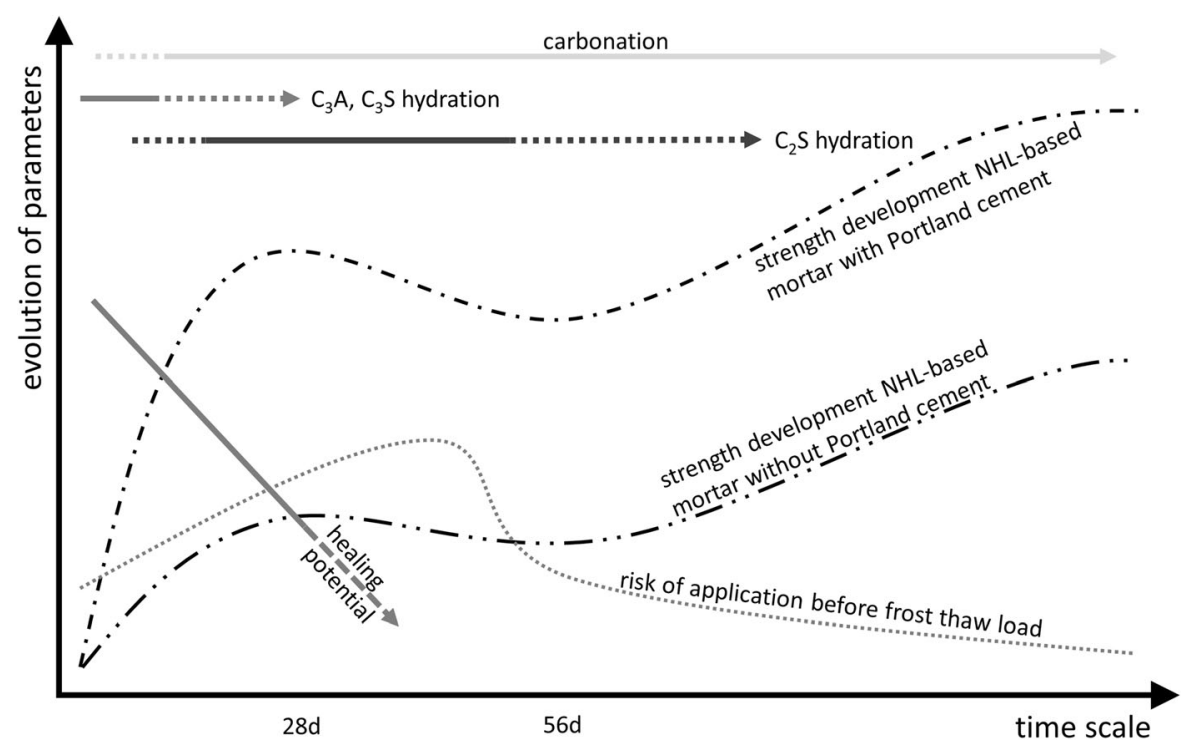

Fig. 8 General schematic drawing of the occurring timedependent reaction behavior in NHL-based mortar materials with and without (white) Portland cement, leading to a specific development of mechanical properties and parallel (healing)

to obtain an appropriate early durability. Nevertheless, it affects other important properties, e.g. the porosity and water transport behavior too. Therefore, it is necessary to consider the surrounding conditions and requirements of the building object to achieve favorable restoration outcomes. The targeted and systematic use of Portland cement is arguable under the following preconditions:

- NHL frequently does not provide the hardening that is considered within the standard ÖNORM EN 459-1 [10] because the (moisture) conditions on building sites differ from the standardized ones. Additionally, its hardening continues over much longer than the standardized 28 days. This implies the justification and the need to consider longer time scales [5]. In this case, the use of Portland cement can help to improve the hardening performance and assures a certain setting speed that can not be provided by the used NHL in some situations. This regards especially zones where the $\mathrm{CO}_{2}$-circulation is hindered through rising damp and when intense frost-thaw loads are expectable shortly (days-weeks) after application.

- Portland cement additions form denser NHL-based mortars that can help to protect the masonry from direct weathering influences like precipitation and effects based on their mineralogical phase transitions. Additionally, we tried to depict a certain damaging risk assessment in regard to the (first) frost-thaw load

moisture. Hence, the use of it is arguable at the crown of the masonry to protect the underlying (historical) substrate from rain and snow, associated with frost-thaw load in the winter. Additionally, it can be used to form a denser area at the bottom of a wall, that will avoid the rising damp uplift and hinder the entry of moisture in the perimeter and socle zone, where potentially dammed-up water occurs.

- Portland cement can help to reinforce unstable parts of a masonry that are statically relevant for the overall construction an require a fast setting. For instance, this is relevant when restoring wall corners that provide stability to the whole wall.

Nevertheless, improving the early frost-thaw durability of NHL-based mortars with Portland cement is a critical issue. It counteracts the water transport ability and drying behavior of the hardened mortars, which is clearly important for several application fields. Additionally, the mentioned material can lead to the displacement of (water, salt) transport processes to adjacent areas, which might react critically [47, 48]. Hence, cement additions should not be used where not necessary or in zones where a high permeability is needed [49]. However, it is difficult to indicate general values for the indication that a material is too dense 
without considering the compatibility with the substrate $[2,50]$. Therefore, the consideration of material characteristics and its function, the application field and the properties of the ancient mortar is necessary to assure a systematic use of pure NHL-based mortars beside Portland cement bearing ones [51].

Therefore, a combination of both material types, namely material $\mathrm{E}$ and $\mathrm{I}$, is also appropriate for cultural heriage applications under certain conditions (see Fig. 5). A case-related assessment of material selection and arrangement is required to anticipate how the cement affects the overall behavior of the masonry. The targeted use of material I is important to assure that a sufficient permeability is given where needed. Additionally, statical advisement and the differentiation between original and rebuilt parts of the masonry is recommended. In these cases, the use of cement in cultural heritage is justifiable and can help to protect the historical sections from being damaged.

Consequently, it would be reasonable for further research to investigate the applied properties of mortars that are based on the binder system of NHL plus Portland cement in more detail. This should be done in consideration of the properties relevant for the real applications in order to better show the limitations of using the presented system.

Acknowledgements This research was supported by the K-Regio EFRE project "Natürlich hydraulische KalkeVerstehen des Systems NHL (NHL)" (EFRE K-Regio 2017-5 NHL). Financial support by the Tyrolean Government (Austria), the European Regional Development Fund (ERDF), and the University of Innsbruck (Austria) is gratefully acknowledged. The authors are thankful for the fruitful collaboration with the project partners, especially the participation of craftsmen, production workers and lab assistants.

\begin{abstract}
Authors' contributions Conceptualization: Frowin Ruegenberg, Franz Brunner; Methodology: Frowin Ruegenberg, Thomas Bidner; Formal analysis and investigation: Frowin Ruegenberg, Franz Brunner, Erik Kirkwood; Writing-original draft preparation: Frowin Ruegenberg; Writing-review and editing: Martin Schidlowski, Erik Kirkwood; Funding acquisition: Anja Diekamp; Resources: Anja Diekamp; Supervision: Anja Diekamp.
\end{abstract}

Funding Open access funding provided by University of Innsbruck and Medical University of Innsbruck. This study has been carried out within the K-Regio project "NHL—Natürlich hydraulische Kalke-Verstehen des Systems NHL" (EFRE K-Regio 2017-5 NHL). The foundation was provided by the European Regional Development Fund (ERDF), which is gratefully acknowledged.
Availability of data and materials The data thapport the findings of this study are available from the corresponding author, Ruegenberg, F., upon reasonable request.

Code availability Not applicable.

\section{Declarations}

Conflict of interest The Authors are affiliated to the organizations mentioned on the title page, which are founded by the European Regional Development Fund (ERDF) in the course of the K-Regio project "NHL-Natürlich hydraulische KalkeVerstehen des Systems NHL” (EFRE K-Regio 2017-5 NHL).

Open Access This article is licensed under a Creative Commons Attribution 4.0 International License, which permits use, sharing, adaptation, distribution and reproduction in any medium or format, as long as you give appropriate credit to the original author(s) and the source, provide a link to the Creative Commons licence, and indicate if changes were made. The images or other third party material in this article are included in the article's Creative Commons licence, unless indicated otherwise in a credit line to the material. If material is not included in the article's Creative Commons licence and your intended use is not permitted by statutory regulation or exceeds the permitted use, you will need to obtain permission directly from the copyright holder. To view a copy of this licence, visit http://creativecommons.org/licenses/by/4.0/.

\section{References}

1. Diekamp A (2014) Bindemitteluntersuchungen an historischen Putzen und Mörteln aus Tirol und Südtirol. Dissertation, University of Innsbruck, Austria

2. Silva BA, Ferreira Pinto AP, Gomes A (2015) Natural hydraulic lime versus cement for blended lime mortars for restoration works. Constr Build Mater 94:346-360. https:// doi.org/10.1016/j.conbuildmat.2015.06.058

3. Cizer O, Van Balen K, Van Gemert D (2010) Competition between hydration and carbonation in hydraulic lime and lime-pozzolana mortars. Adv Mater Res 133-134:241-246. https://doi.org/10.4028/www.scientific.net/AMR.133-134. 241

4. Odler I (2019) 6-Hydration, setting and hardening of Portland cement. In: Hewlett PC, Liska M (eds) Lea's chemistry of cement and concrete, 5th edn. ButterworthHeinemann, Oxford

5. Figueiredo C, Ball R, Lawrence R (2016) Is EN459-1 fit for purpose in the context of conservation? In: 36 th cement and concrete science conference. Cardiff University, Cardiff

6. Grilo J, Santos Silva A, Faria P, Gameiro A, Veiga MR, Velosa AL (2014) Mechanical and mineralogical properties of natural hydraulic lime-metakaolin mortars in different curing conditions. Constr Build Mater 51:287-294. https:// doi.org/10.1016/j.conbuildmat.2013.10.045

7. Hees RPJ, Groot C, Hughes J, Van Balen K, Bicer-Simsir B, Binda L, Elsen $\mathrm{J}$, Von Konow $\mathrm{T}$, Lindqvist $\mathrm{J}$, 
Maurenbrecher P, Papayianni I, Subercaseaux M, Tedeschi C, Toumbakari EE, Thompson M, Valek J, Veiga MR (2012) RILEM TC 203-RHM: Repair mortars for historic masonry. Repair mortars for historic masonry. From problem to intervention: a decision process. Mater Struct 45:1295-1302. https://doi.org/10.1617/s11527-012-9917-z

8. Brunner F (2021) Franz Brunner, restorer, pers. comm.

9. Teutonico JM, Mc Caig I, Burns C, Ashurst J (1993) The Smeaton project: factors affecting the properties of limebased mortars. APT Bull 25:32-49

10. ÖNORM EN 459-1 (2015) Building lime-Part 1: Definitions, specifications and conformity criteria. Austrian Standards Institute, Vienna

11. O'Hare, G. (1995) Lime Mortars and Renders-The Relative Merits of Adding Cement. The Building Conservation Directory. https://www.buildingconservation.com/articles/ cement/cement.htm

12. ÖNORM EN 998-2 (2017) Specification for mortar for masonry-Part 2: Masonry mortar. Austrian Standards Institute, Vienna

13. OFI (2015) IBF-Richtlinie - Beschleunigter Alterungstest zur Überprüfung der Streusalzverträglichkeit von Gebäudesockelmaterialien. OFI Technologie \& Innovation $\mathrm{GmbH}$, Vienna

14. Knöfel D, Schubert P (1993) Mörtel und Steinergänzungsstoffe in der Denkmalpflege. Verlag Ernst \& Sohn, Berlin

15. Ruegenberg F, Schidlowski M, Bader T, Diekamp A (2021) Assessing the influence of the mixing method on porosity and durability of NHL-based renders based on key parameters. Constr Build Mater 276:122197. https://doi.org/10. 1016/j.conbuildmat.2020.122197

16. Ruegenberg F, Schidlowski M, Bader T, Diekamp A (2021) NHL-based mortars in restoration: frost-thaw and salt resistance testing methods towards a field related application. Case Studies in Construction Materials 14:e00531. https://doi.org/10.1016/j.cscm.2021.e00531

17. Papayianni I, Hughes J (2018) Testing properties governing the durability of lime-based repair mortars. RILEM Technical Lett 3:135-139. https://doi.org/10.21809/ rilemtechlett.2018.81

18. Frick, Schmid-Pittl K (2006) Thaur, Burgruine Thaur. INV. Nr. 61642 Tiroler Kunstkataster - Land Tirol, Innsbruck, Austria

19. Schidlowski M, Ruegenberg F, Bader T, Diekamp A (2020) A study for assessing the relationship between calcination temperature and mineralogical composition of natural hydraulic limes (NHL). In: Siegesmund S, Middendorf B (eds) Monument future. Decay and conservation of stone. Proceedings of the 14th international congress on deterioration and conservation of stone. Mitteldeutscher Verlag (mdv), Halle, 1065-1070

20. ÖNORM EN 197-1 (2018) Cement-Part 1: Composition, specifications and conformity criteria for common cements. Austrian Standards Institute, Vienna

21. ÖNORM EN 1015-11 (2018) Methods of test for mortar for masonry-Part 11: Determination of flexural and compressive strength of hardened mortar. Austrian Standards Institute, Vienna

22. Garijo L, Zhang X, Ruiz G, Ortega JJ, Wu Z (2018) The effects of dosage and production process on the mechanical and physical properties of natural hydraulic lime mortars. Constr Build Mater 169:325-334. https://doi.org/10.1016/j. conbuildmat.2018.03.016

23. Balksten K, Strandberg-de Bruijn P (2021) Understanding deterioration due to salt and ice crystallization in Scandinavian massive brick masonry. Heritage 4:349-370. https:// doi.org/10.3390/heritage4010022

24. ÖNORM EN 196-1 (2016) Methods of testing cementPart 1: Determination of strength. Austrian Standards Institute, Vienna

25. ÖNORM EN 1015-3 (2007) Methods of test for mortar for masonry-Part 3: Determination of consistence of fresh mortar (by flow table). Austrian Standards Institute, Vienna, Austria.

26. ÖNORM EN 1015-6 (2007) Methods of test for mortar for masonry-Part 6: Determination of bulk density of fresh mortar. Austrian Standards Institute, Vienna

27. ÖNORM EN 1015-7 (1999) Methods of test for mortar for masonry-Part 7: Determination of air content of fresh mortar. Austrian Standards Institute, Vienna

28. ÖNORM EN 1052-2 (2017) Methods of test for masonryPart 2: Determination of flexural strength. Austrian Standards Institute, Vienna

29. ÖNORM EN 1936 (2007) Natural stone test methodsdetermination of real density and apparent density, and of total and open porosity. Austrian Standards Institute, Vienna

30. Hirschwald J (1912) Handbuch der bautechnischen Gesteinsprüfung. Borntraeger Verlag, Berlin

31. Mirwald PW (1997) Physikalische Eigenschaften von Gesteinen. In: EV, B.d.S.-u.B. (ed) Naturwerkstein und Umweltschutz in der Denkmalpflege. Ebner Media Group $\mathrm{GmbH} \& \mathrm{Co} \mathrm{KG}$, Ulm

32. RILEM Comission 25-PEM (1980) RILEM Test No. II.1. Saturation coefficient. - Recommandations provisoires. Essais recommandés pour mesurer l'altération des pierres et évaluer l'éfficacité des méthodes de traitement. -Matériaux et Construction 13 (75).

33. ÖNORM EN 1015-18 (2003) Methods of test for mortar for masonry-Part 18: Determination of water absorption coefficient due to capillary action of hardened mortar. Austrian Standards Institute, Vienna

34. Botas S, Rato V, Faria P (2010) Testing the Freeze/Thaw Cycles in Lime Mortar. In: Válek J, Groot C, Hughes J (eds) Historic mortars conference, RILEM proceedings Pro 078: HMC2010, 2nd historic mortars conference and RILEM TC 203-RHM final workshop, Prague, pp 417-425

35. Steinbruch Walser GmbH \& Co KG (2021) website of the company, http://steinbruch-walser.at/. Accessed 18 Feb 2021

36. Wetter.com (2020) Wetterrückblick der Region Innsbruck. Daten der Station INNSBRUCK-FLUGHAFEN (AUTOMAT), https://www.wetter.com/wetter_aktuell/rueckblick/ oesterreich/innsbruck/ATAT30256.html. Accessed 04 May 2020

37. DIN 1053-1 (1996) Masonry-part 1: design and construction. German Standards Institute, Berlin

38. Verein Chronos Thaur (2021) Burgruine Thaur. Website Verein Chronos Thaur - Verein für Dorfgeschichte, http:// www.chronos-thaur.at/highlights/burgruine-thaur. Accessed 18 Feb 2021 
39. Wetter.com (2021) Wetterrückblick der Region Innsbruck. Daten der Station INNSBRUCK-FLUGHAFEN (AUTOMAT), https://www.wetter.com/wetter_aktuell/rueckblick/ oesterreich/innsbruck/ATAT30256.html. Accessed 30 March 2021

40. DIN 1045-3 (2012) Concrete, reinforced and prestressed concrete structures-Part 3: Execution of structures-Application rules for DIN EN 13670. German Standards Institute, Berlin

41. Penas F (2008) Hydraulic lime mortars for wall rendering. https://Fenix.tecnico.ulisboa.pt

42. Goni S, Puertas F, Hernández M, Palacios M, Guerrero A, Dolado J, Zanga B, Baroni F (2010) Quantitative study of hydration of $\mathrm{C} 3 \mathrm{~S}$ and $\mathrm{C} 2 \mathrm{~S}$ by thermal analysis-evolution and composition of C-S-H gels formed. J Therm Anal Calorim 102:965-973. https://doi.org/10.1007/s10973-0100816-7

43. Allen G, Ball R (2012) Mechanical properties of hydraulic lime mortars. In: 4th Portuguese congress on mortars and ETICS, Coimbra, Portugal

44. Arandigoyen M, Alvarez JI (2006) Blended pastes of cement and lime: pore structure and capillary porosity. Appl Surf Sci 525:8077-8085. https://doi.org/10.1016/j.apsusc. 2005.10.019

45. Künzel H (2014) Problembereich aufsteigende Feuchte. Bausubstanz 3:34-40

46. Ruegenberg F, Schidlowski M, Bader T, Diekamp A (2019) NHL-based plasters and renders-Assessing the influence of mixing method on workability and hardened mortar properties. In: Alvarez JI, Fernandes JM, Navarro I, Duran A, Sirera R (eds), RILEM PRO 130: proceedings of the 5th Historic Mortars Conference (HMC 2019). 19-21 June
2019 Pamplona, Spain. Bagneux: RILEM Publications S.A.R.L. (= RILEM Proceedings PRO, 130), pp 1195-1214

47. Franzoni E (2014) Rising damp removal from historical masonries: a still open challenge. Constr Build Mater 54:123-136. https://doi.org/10.1016/j.conbuildmat.2013. 12.054

48. Bidner T (2006) Dürfen alte Bauwerke feucht bleiben? Applica 10:2-7

49. Maurenbrecher P, Groot C, Hughes J, Van Balen K, BicerSismir B, Binda L, Elsen J, Hees RPJ, Von Konow T, Lindquist JE, Papayianni I, Subercaseaux M, Tedeschi C, Toumbakari EE, Thompson M, Válek J, Veiga MR (2012) RILEM TC 203-RHM: Repair mortars for historic masonry. Requirements for repointing mortars for historic masonry. Mater Struct 45:1303-1309. https://doi.org/10.1617/ s11527-012-9849-7

50. Delgado Rodrigues J, Grossi A (2007) Indicators and ratings for the compatibility assessment of conservation actions. J Cult Herit 8(1):32-43. https://doi.org/10.1016/j.culher. 2006.04.007

51. Hughes J, Groot C, Van Balen K, Bicer-Sismir B, Binda L, Elsen J, Hees RJ, Von Konow T, Lindquist JE, Maurenbrecher P, Papayianni I, Subercaseaux M, Tedeschi C, Toumbakari EE, Thompson M, Válek J, Veiga MR (2012) RILEM TC 203-RHM: Repair mortars for historic masonry. The role of mortar in masonry: an introduction to the requirements for the design of repair mortars. Mater Struct 45:1287-1294. https://doi.org/10.1617/s11527-012-9916-0

Publisher's Note Springer Nature remains neutral with regard to jurisdictional claims in published maps and institutional affiliations. 